\title{
A Case of Sudden Desaturation and Cyanosis
}

Srilekha Puranam, MD ${ }^{1}$ Irene M. Spinello, $\mathrm{MD}, \mathrm{FCCP}^{2,3,4}$

\author{
${ }^{1}$ Department of Medicine, Kern Medical Center, Bakersfield, California. \\ ${ }^{2}$ David Geffen School of Medicine at the University of California, Los Angeles (UCLA), Los Angeles, California. \\ ${ }^{3}$ Division of Critical Care and Pulmonary Services, Kern Medical Center, Bakersfield, California. \\ ${ }^{4}$ Intensive Care, Kern Medical Center, Bakersfield, California.
}

Disclosure: Nothing to report.

Journal of Hospital Medicine 2009;4:387-389. @ 2009 Society of Hospital Medicine.

KEYWORDS: benzocaine, "chocolate-brown” arterial blood, cyanosis, methemoglobinemia, methylene blue, "oxygenation gap”.

A 38-year-old Hispanic man was admitted to the telemetry floor with diagnosis of pericarditis. Blood cultures revealed methicillin-sensitive Staphylococcus aureus and the patient was started on nafcillin. Despite appropriate antibiotic therapy, the patient remained febrile. Transesophageal echocardiogram (TEE) was performed to evaluate for endocarditis. An hour after the TEE, patient started to desaturate and complained of shortness of breath. At this point, the patient was afebrile, with a pulse rate of 110 beats/minute and blood pressure of $97 / 63 \mathrm{~mm}$ Hg. Oxygen saturation by pulse oximetry of $82 \%$ on room air progressively declined even with administration of supplemental oxygen to $77 \%$, necessitating intubation. Despite mechanical ventilation with $100 \%$ oxygen delivery, the patient remained cyanotic, with pulse oximetry reading of $69 \%$, and with the arterial blood obtained from the patient at this time for laboratory analysis appearing brown in color.

Based on the temporal correlation of benzocaine spray used during TEE and the symptoms-cyanosis, hypoxia despite $100 \%$ fraction of inspired oxygen $\left(\mathrm{FiO}_{2}\right)$, and "chocolate-brown" arterial blood-a diagnosis of methemoglobinemia was made. The patient's methemoglobin level was reported at $41 \%$ (normal range, $0-3 \%$ ). The patient received methylene blue, recovered rapidly, and was extubated the next day. Subsequent methemoglobin level obtained less than 24 hours later was reduced to $0.8 \%$. Two days later the patient was discharged to home.

\section{Discussion}

Methemoglobin is the state in which ferrous $\left(\mathrm{Fe}^{2+}\right)$ ions of heme are oxidized to the ferric state $\left(\mathrm{Fe}^{3+}\right)$. Because red blood cells are continuously exposed to various oxidative stresses, a methemoglobinemia level of approximately $1 \%$ is present in normal individuals at baseline. This low level is maintained through reduction by enzyme systems within the erythrocyte. The most important is the reduced nicotinamide adenine dinucleotide (NADH)-cytochrome- $b 5$ reductase system. ${ }^{1}$ Others, functioning mainly as reserve systems, are ascorbic acid, reduced glutathione, and reduced nicotinamide adenine dinucleotide phosphate (NADPH)-methemo- globin reductase. The latter requires a natural cofactor or an autooxidizable dye such as methylene blue for activity.

Methemoglobinemia can be congenital or acquired. Congenital methemoglobinemia is very rare and is due to a cytochrome-b5 reductase deficiency or presence of an abnormal hemoglobin M molecule. ${ }^{2}$ Acquired methemoglobinemia, the more common type, results from exposure to chemicals that cause more rapid accumulation of methemoglobin than the rate at which methemoglobin can be reduced. Many chemical and environmental agents can cause acquired methemoglobinemia (Table 1). Local anesthetics are the most common hospital-based pharmacologic agents to cause methemoglobinemia. Prilocaine has been implicated most frequently, especially in newborns. Prilocaine-induced methemoglobinemia is dose-dependent and occurs when doses used exceed $600 \mathrm{mg}$ in a 24-hour period. Lidocaine is a rare cause of methemoglobinemia, but comorbidities like renal failure and use of other local anesthetics like benzocaine will increase the chances of methemoglobinemia. Benzocaine has been reported to cause methemoglobinemia after its use as a lubricant on endotracheal, bronchoscopic, and nasogastric or orogastric tubes, but more commonly after its use as a spray. Benzocaine is lipophilic and may continue to enter the bloodstream from adipose tissue after methylene blue concentrations are no longer therapeutic.

Clinical presentation varies based on methemoglobin levels. Early symptoms of methemoglobinemia, when the blood contains $15 \%$ to $50 \%$ methemoglobin, include nonspecific headache, fatigues, dyspnea, and lethargy. As the amount of methemoglobin in the blood exceeds $50 \%$, the patients develop more serious neurological symptoms, ranging from confusion to seizures, respiratory depression, and death (Table 2). Clinical interpretation of methemoglobin levels must take into account the total hemoglobin value because anemic patients will have proportionately less functional hemoglobin. ${ }^{3}$ Methemoglobinemia that develops rapidly will be clinically more severe than a similar degree that develops gradually. The acute accumulation of $<30 \%$ methemoglobinemia is usually well tolerated in the nonanemic patient. 


\section{TABLE 1. Etiologies of Methemoglobinemia}

\begin{tabular}{|c|c|}
\hline Name & Key Features \\
\hline Naphthalene & Coal tar, mothballs. Newborns are at increased risk for methemoglobinemia \\
\hline Aniline/aminophenols & Laundry ink. Aniline-induced methemoglobinemia is less responsive to methylene blue \\
\hline Chlorates & Matches, explosives, pyrotechnics, weed killers. Also cause intravascular hemolysis and toxic nephritis \\
\hline & $\begin{array}{l}\text { Lidocaine: Very rarely causes methemoglobinemia alone. Comorbidities like renal failure and use of other local anesthetics will increase } \\
\text { the chances of methemoglobinemia. Prilocaine: Dose-dependent. Occurs when doses used exceed } 600 \mathrm{mg} \text {. Newborns are at } \\
\text { higher risk }\end{array}$ \\
\hline Primaquine & $\begin{array}{l}\text { Primaquine-induced methemoglobinemia, although almost universal with clinical doses, seems to be mild, self-limited, and tolerated without } \\
\text { symptoms or signs of cyanosis in otherwise healthy people }\end{array}$ \\
\hline Nitrites (amyl and butyl) & Amyl nitrite: Used in treating angina. Butyl nitrite: Used in room deodorizers. Both drugs are used for their alleged sexual enhancing properties \\
\hline Nitroprusside & $\begin{array}{l}\text { Methemoglobinemia occurs in patients who have received a dose larger than } 10 \mathrm{mg} / \mathrm{kg} \text { in } 1 \text { day. It takes } 16 \text { hours of continuous infusion at the } \\
\text { maximum rate of } 10 \mu \mathrm{g} / \mathrm{kg} / \text { minute to reach the total accumulated dose }\end{array}$ \\
\hline Phenazopyridine & $\begin{array}{l}\text { Increased incidence of methemoglobinemia in patients with renal failure. Drug also causes hemolytic anemia and turns the urine orange-yellow } \\
\text { in color. One of its metabolites is aniline }\end{array}$ \\
\hline Metoclopromide & Overdose in infants causes methemoglobinemia \\
\hline Trimethoprim & Methemoglobinemia usually occurs after prolonged periods of administration. Caution when used with dapsone \\
\hline
\end{tabular}

\section{TABLE 2. Clinical Presentation}

\begin{tabular}{ll}
$\begin{array}{l}\text { Level of } \\
\text { methemoglobinemia }\end{array}$ & Symptoms \\
\hline $0-15 \%$ & $\begin{array}{l}\text { No signs or symptoms } \\
\text { Cyanosis and "chocolate brown" blood }\end{array}$ \\
$15-20 \%$ & $\begin{array}{l}\text { Headache, fatigues, dyspnea, and lethargy } \\
\text { Serious neurological symptoms ranging from confusion } \\
\text { to seizures; respiratory depression and death }\end{array}$ \\
\hline $50 \%$ &
\end{tabular}

The suspicion for methemoglobinemia should be raised in the presence of dark or "chocolate-brown" arterial blood that does not become red with exposure to air. ${ }^{4}$ Dark-colored blood from patients with hypoxia should redden with exposure to air; blood darkened by methemoglobin does not. The suspicion for methemoglobinemia should also be raised in the presence of a "saturation gap," when the measured oxygen saturation of blood by pulse oximetry is less than the oxygen saturation calculated by routine blood gas analysis by more than $5 \%{ }^{5}$ The oxygen saturation on arterial blood gas is calculated from partial pressure of arterial oxygen $\left(\mathrm{PaO}_{2}\right)$ and $\mathrm{pH}$. Since $\mathrm{PaO}_{2}$ is within normal limits in methemoglobinemia, it leads to a normal, though inaccurate, calculated oxygen saturation. Multiple-wavelength cooximetry is the accepted standard for confirming and quantifying methemoglobinemia. ${ }^{6}$ This assay involves measuring methemoglobin at its peak absorbance of $630 \mathrm{~nm}$ and requires the addition of cyanide to convert methemoglobin to cyanomethemoglobin, which absorbs at shorter wavelengths, resulting in an absorbance decrease at $630 \mathrm{~nm}$ due to the disappearance of methemoglobin. Hyperlipidemia and intravenous administration of methylene blue or other dyes may interfere with cooximetry measurements.

In asymptomatic patients with acute methemoglobinemia, discontinuation of the offending drug and proper monitoring is sufficient. In patients who are symptomatic, in addition to supplemental oxygen, methylene blue should be used to enhance the reducing capacity of erythrocytes. Methylene blue, given intravenously in a dose of $1 \mathrm{mg} / \mathrm{kg}$ over 5 minutes, acts as an electron acceptor, enhances the NADPH pathway, and rapidly reduces methemoglobin to hemoglobin. ${ }^{7}$ However, methylene blue should not be used in patients with glucose-6-phosphate dehydrogenase deficiency as it can cause life-threatening hemolysis. In these patients, ascorbic acid should be used. Hyperbaric oxygen or exchange transfusion can also be used. In patients who are in shock secondary to the methemoglobinemia, blood transfusion or exchange transfusion is helpful.

\section{Summary}

Agents that inflict large oxidative stress, such as topical anesthetics, can cause methemoglobinemia. A frequentlyused topical anesthetic agent like benzocaine is a common cause of methemoglobinemia. The most characteristic findings of methemoglobinemia are blue-gray or brown-gray cyanosis of the skin, lips, and nail beds, dark brown color of 
the blood, and "saturation gap." Symptomatic patients should be given methylene blue intravenously.

\section{Address for correspondence and reprint requests:}

Irene M. Spinello, 1700 Mt. Vernon Ave, Bakersfield, CA 93306;

Telephone: 661 326-2200; E-mail: spinelloi@kernmedctr.com

Received 17 July 2008; revision received 25 October 2008; accepted

23 November 2008.

\section{References}

1. Umbreit J. Methemoglobin—it's not just blue: a concise review. Am J Hematol. 2007;82(2):134-144.

2. Griffey RT, Brown DF, Nadel ES. Cyanosis. J Emerg Med. 2000;18(3):369-371.
3. Kane GC, Hoehn SM, Behrenbeck TR, Mulvagh SL. Benzocaine-induced methemoglobinemia based on the Mayo Clinic experience from 28,478 transesophageal echocardiograms: incidence, outcomes, and predisposing factors. Arch Intern Med. 2007;167(18):1977-1982.

4. Wright RO, Lewander WJ, Woolf AD. Methemoglobinemia: etiology, pharmacology, and clinical management. Ann Emerg Med. 1999;34(5): 646-656.

5. Akhtar J, Johnston BD, Krenzelok EP. Mind the gap. J Emerg Med. 2007; 33(2):131-132.

6. Konig MW, Dolinski SY. A 74-year-old woman with desaturation following surgery. Co-oximetry is the first step in making the diagnosis of dyshemoglobinemia. Chest. 2003;123(2):613-616.

7. Clifton J 2nd, Leikin JB. Methylene blue. Am J Ther. 2003;10(4): 289-291. 